\title{
OXIDATION OF GAS TURBINE SEAL RING ALLOYS AND ITS EFFECT ON
}

\author{
MECHANICAL PROPERTIES
}

\author{
J. J. BARNES and S. K. SRIVASTAVA \\ Haynes International, Inc. \\ 1020 West Park Avenue \\ Kokomo, IN 46904
}

\begin{abstract}
The effect of oxidation resistance on the mechanical properties of two gas turbine seal ring alloys at $650^{\circ} \mathrm{C}$ and $760^{\circ} \mathrm{C}$ was investigated. Alloy 909 , an Fe-Ni-Co alloy which has much higher tensile strength than 242 alloy, was found to have poor oxidation resistance which is reflected in reduced stress rupture strength and low cycle fatigue resistance. The deterioration in mechanical properties was caused by cracking of the oxide scale and subscale under tensile stress. The 242 alloy, a NiMo-Cr alloy, exhibited good oxidation resistance and good long term mechanical properties.
\end{abstract}




\section{Introduction}

Environmental resistance, high-temperature strength and low thermal expansion are critical requirements for gas turbine seal ring materials. For temperatures of $700^{\circ} \mathrm{C}$ and above, alloys of the Ni-Mo-Cr system, such as HASTELLOY ${ }^{\circledR}$ alloys $\mathrm{S}$ and $\mathrm{N}$, have been used successfully. For lower temperatures, a new member of the $\mathrm{Ni}-\mathrm{Mo}-\mathrm{Cr}$ family has been introduced recently : HAYNES $242^{\mathrm{TM}}$ alloy. This is a long-range-order strengthened alloy which is strengthened by domains of $\mathrm{Ni}_{2}(\mathrm{Mo}, \mathrm{Cr})$ and has good oxidation resistance due to the presence of chromium $(1,2)$. Alloys of the Fe-Ni-Co system have also been used for gas turbine seal ring applications. The principal attributes of alloys in this system, such as alloy 909 , are low thermal expansion coefficient and good high-temperature strength. However, due to the absence of chromium the environmental resistance of such alloys is lacking.

Oxidation resistance is clearly an important factor in the behavior of a material exposed at high temperatures. Chaku and McMahon (3) have demonstrated the detrimental effect of oxidation on the creep resistance of superalloys. In high temperature low cycle fatigue, Coffin (4-7) and Woodford (8) have shown that oxidation contributes significantly to damage in superalloys.

This paper examines the oxidation resistance of alloy 909 and 242 alloy in relation to their mechanical properties. The baseline oxidation resistance of the alloys was measured through static oxidation tests at $650^{\circ} \mathrm{C}$ and $760^{\circ} \mathrm{C}$ and dynamic oxidation tests at $760^{\circ} \mathrm{C}$. Mechanical property testing included tensile and stress rupture testing at $650^{\circ} \mathrm{C}$ and $760^{\circ} \mathrm{C}$ and stress-controlled fatigue testing at $650^{\circ} \mathrm{C}$. After testing, samples were examined using metallographic techniques and SEM/ EDAX.

\section{Experimental}

The chemical compositions of the alloys tested are given in Table I. Static oxidation tests were

Table I Chemical Compositions of the alloys tested (wt\%)

\begin{tabular}{lcccccccl}
\hline Alloy & Ni & Mo & Cr & Co & Fe & C & Others \\
\hline HAYNES $^{\oplus} 242$ alloy & & Bal. & 25 & 8 & - & $2 *$ & 0.03 & - \\
INCOLOY & alloy 909 & 38 & - & - & 13 & Bal. & 0.01 & $4.7 \mathrm{Nb}, 1.5 \mathrm{Ti}, 0.4 \mathrm{Si}$ \\
* maximum & \\
HAYNES and 242 are trademarks of Haynes International, Inc. \\
INCOLOY is a registered trademark of the Inco Family of Companies.
\end{tabular}

conducted at $650^{\circ} \mathrm{C}$ and $760^{\circ} \mathrm{C}$ in flowing air. The samples were cycled to room temperature once a week for the $650^{\circ} \mathrm{C}$ test and once a day for the $760^{\circ} \mathrm{C}$ test. Weight measurements were made at regular intervals. The samples were descaled at the conclusion of the tests and the metal loss and depth of internal attack determined. 
The dynamic oxidation test at $760^{\circ} \mathrm{C}$ was conducted in a burner rig. Samples were exposed to a high velocity $(0.3 \mathrm{Mach})$ combustion environment and cycled to about $250^{\circ} \mathrm{C}$ every 30 minutes. The samples were removed from the test at intervals for weight measurement and, after test, the samples were examined metallographically to determine metal loss and depth of internal attack.

Tensile tests were conducted at 538,650 and $760^{\circ} \mathrm{C}$. Stress rupture tests were conducted at 538 , 650,704 and $760^{\circ} \mathrm{C}$ on smooth notch bar specimens taken from a section of a hot-forged and rolled ring. Fatigue tests were conducted at $650^{\circ} \mathrm{C}$ under stress-controlled conditions on double-notched specimens. The specimens were examined after testing using metallographic techniques.

\section{Results}

\section{Oxidation Tests}

Figure 1 shows the weight change vs. time data from the static oxidation test at $650^{\circ} \mathrm{C}$. The 909 sample oxidized at a much faster rate than the 242 alloy. The metallographic measurements from the test are given in Table II. The 242 alloy sample had no measurable metal loss or maximum metal affected. In contrast, the maximum metal affected (metal loss + maximum internal penetration) for alloy 909 was almost $200 \mu \mathrm{m}$.

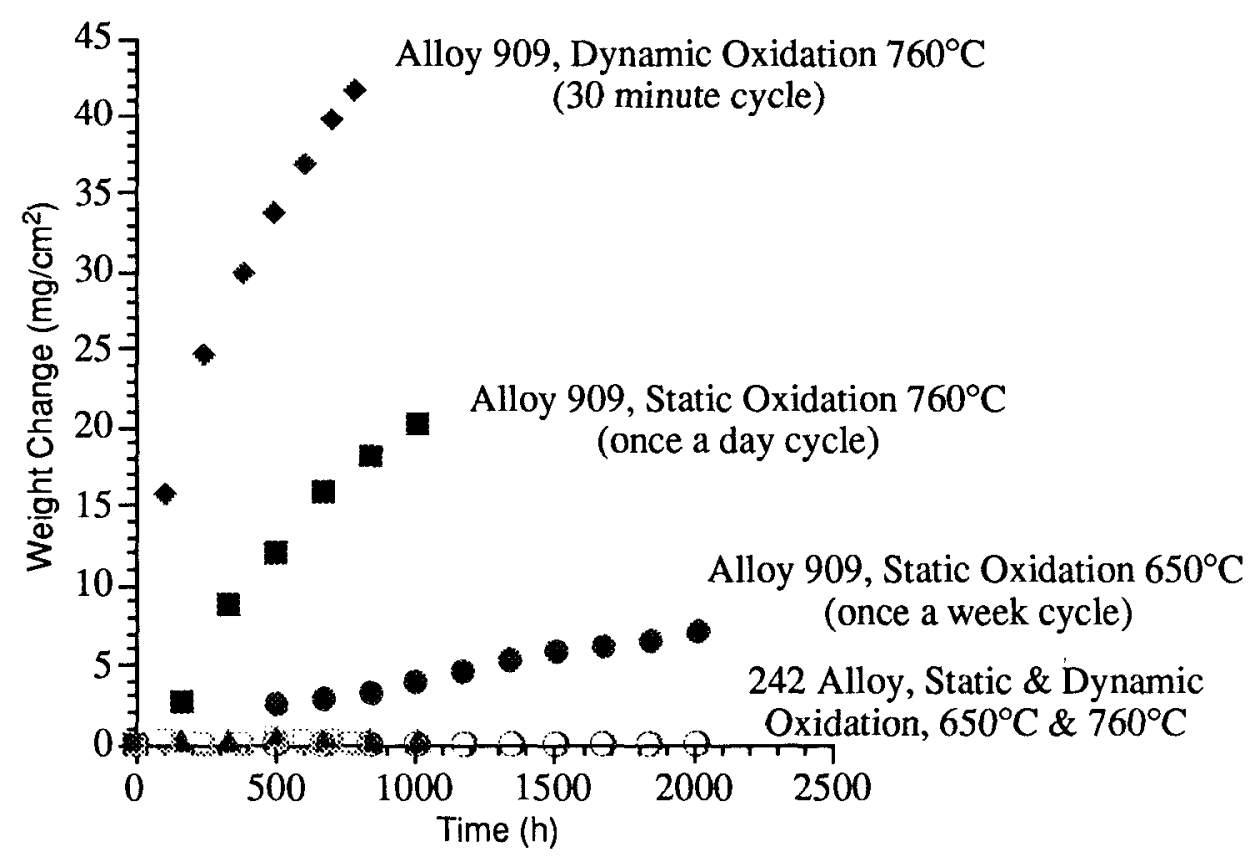

Figure 1 - Oxidation data from static and dynamic tests at $650^{\circ} \mathrm{C}$ and $760^{\circ} \mathrm{C}$.

Samples from the static oxidation test at $650^{\circ} \mathrm{C}$ were examined using optical metallography and SEM/EDAX. The surface oxide on alloy 909 was found to be cracked and had spalled in many areas. EDAX analysis showed it to be rich in Fe and Co. Beneath the outer scale there was an enrichment in Fe. A cross-section (Figure 2) revealed a multi-layered internal oxide. The thick outer scale was rich in $\mathrm{Fe}$ and $\mathrm{Co}$ at the scale/gas interface and was enriched in $\mathrm{Fe}, \mathrm{Ni}, \mathrm{Nb}$ and $\mathrm{Ti}$ at the inner interface. Beneath the scale was a layer which contained oxide rich in $\mathrm{Fe}$ and $\mathrm{Ni}$ and entrapped metal islands which were rich in $\mathrm{Ni}$. Beneath this was another layer of internal oxide. In many areas there was an interfacial crack between the layers and delamination had occurred. 
In contrast to alloy 909 , the 242 alloy showed no evidence of spalling or cracking of the oxide scale. The alloy formed a thin, adherent scale which was rich in $\mathrm{Cr}$ and $\mathrm{Ni}$.

Table II Metallographic Data from Static Oxidation Tests at $650^{\circ} \mathrm{C}$ (once a week cycle) and $760^{\circ} \mathrm{C}$ (once a day cycle)

\begin{tabular}{lcccc}
\hline Alloy & $\begin{array}{c}\text { Test } \\
\text { Temp. }\left({ }^{\circ} \mathrm{C}\right)\end{array}$ & Time $(\mathrm{h})$ & Metal Loss $(\mu \mathrm{m})$ & $\begin{array}{c}\text { Max. Metal } \\
\text { Affected }(\mu \mathrm{m})\end{array}$ \\
\hline 242 & 650 & 2016 & 0 & 0 \\
909 & & 40.6 & 198.1 \\
242 & 760 & 1008 & 7.6 & 12.7 \\
909 & & & 63.5 & 190.5 \\
\hline
\end{tabular}

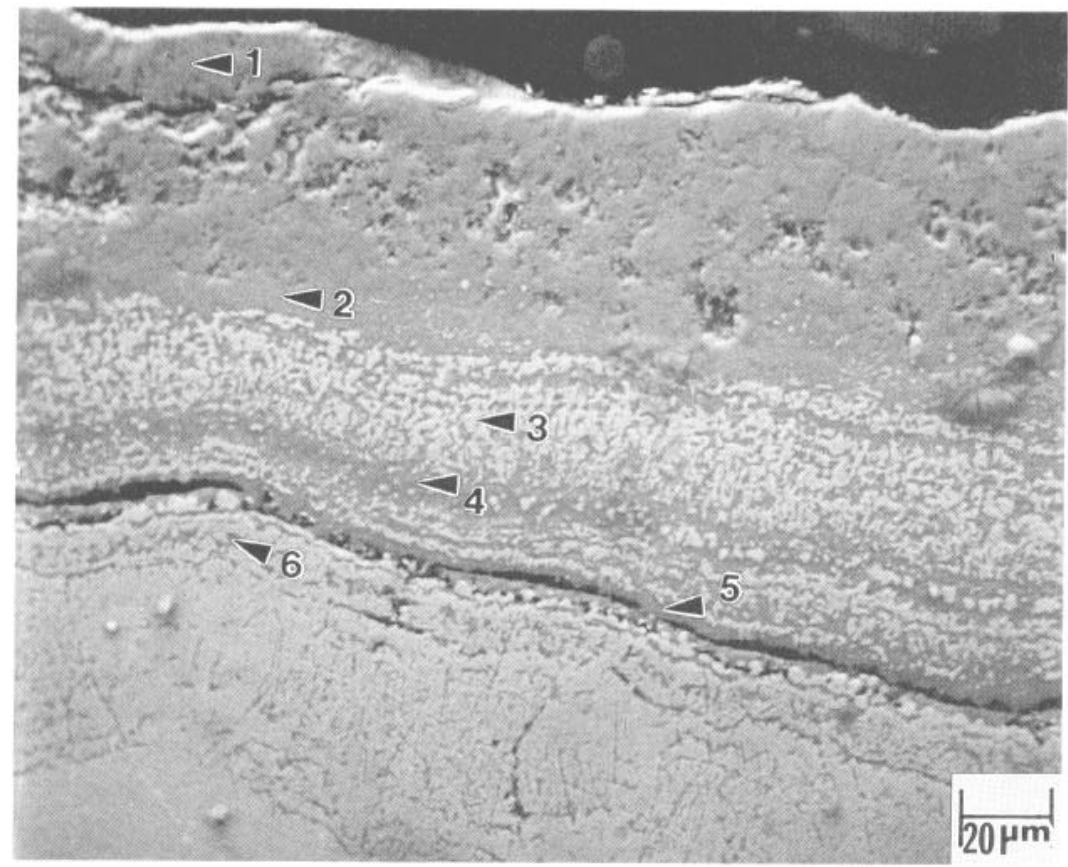

Semi-Quantitative Analysis (\%)

\begin{tabular}{|cccccc|}
\hline Point & $\mathrm{Fe}$ & $\mathrm{Co}$ & $\mathrm{Ni}$ & $\mathrm{Nb}$ & $\mathrm{Ti}$ \\
\hline 1 & 69.9 & 30.1 & - & - & - \\
2 & 79.3 & 5.5 & 9.6 & 3.7 & 1.9 \\
3 & 21.0 & 11.7 & 64.4 & 1.3 & 1.6 \\
4 & 89.5 & - & 9,5 & 1.0 & - \\
5 & 92.0 & - & 7.2 & 0.9 & - \\
6 & 48.3 & 9.6 & 24.5 & 10.4 & 7.2
\end{tabular}

Figure 2 - SEM/EDAX of oxide scale on alloy 909 after static oxidation testing at $650^{\circ} \mathrm{C} / 2016$ hours/once a week cycle. 
The weight changes from the static oxidation test at $760^{\circ} \mathrm{C}$ are shown in Figure 1 . The 242 alloy exhibited a very low rate of oxidation while alloy 909 oxidized at a relatively rapid parabolic rate. The parabolic rate constant, $\mathrm{k}_{\mathrm{p}}$, according to the equation :

$$
(\Delta \mathrm{W} / \mathrm{A})^{2}=\mathrm{k}_{\mathrm{p}} \times \mathrm{t}
$$

where $\Delta \mathrm{W} / \mathrm{A}$ is weight gain per unit area and $\mathrm{t}$ is time, was calculated as $1.4 \times 10^{-4} \mathrm{mg}^{2} \mathrm{~cm}^{-4} \mathrm{~s}^{-1}$. The metallographic measurements from the test are given in Table II. The 242 alloy had maximum metal affected of $12.7 \mu \mathrm{m}$, whereas the 909 sample suffered attack to a depth of $190.5 \mu \mathrm{m}$. It should be noted that the depth of attack at $760^{\circ} \mathrm{C}$ was approximately the same as that at $650^{\circ} \mathrm{C}$, although the duration of the test at $760^{\circ} \mathrm{C}$ was half that of the test at $650^{\circ} \mathrm{C}$.

The weight gain data from the dynamic oxidation test at $760^{\circ} \mathrm{C}$ are shown in Figure 1 . The 909 sample exhibited a high parabolic rate of oxidation while the 242 alloy oxidized at a very low rate. The parabolic rate constant, $\mathrm{k}_{\mathrm{p}}$, for the alloy 909 sample was calculated as $6.0 \times 10^{-4} \mathrm{mg}^{2} \mathrm{~cm}^{-4}$ $\mathrm{s}^{-1}$. The metallographic measurements on the exposed specimens are given in Table III. The metal loss for 909 was less than that for 242 alloy but the maximum metal affected for 909 was much greater than that for 242 alloy.

Table III Metallographic Data from Dynamic Oxidation specimens tested at $760^{\circ} \mathrm{C}(30$ minute cycles)

\begin{tabular}{ccc}
\hline Alloy & Metal Loss $(\mu \mathrm{m})$ & $\begin{array}{c}\text { Max. Metal } \\
\text { Affected }(\mu \mathrm{m})\end{array}$ \\
\hline 242 & 27.9 & 40.6 \\
909 & 7.6 & 325.1 \\
\hline
\end{tabular}

Optical micrographs from the samples after dynamic oxidation testing at $760^{\circ} \mathrm{C}$ are shown in Figure 3. The 242 alloy showed very little evidence of oxidation whereas the 909 sample exhibited extensive scaling and internal oxidation and had cracks extending through the internal oxidation zone. SEM/EDAX analysis of the scale on alloy 909 indicated that the scale was rich in Fe and was apparently mostly iron oxide. Iron oxide also predominated within the alloy. The islands of remaining metal were rich in Ni. The alloy exhibited interfacial cracks in addition to cracks which extended deep into the material. These were filled with an Fe-rich oxide. The cracks did not extend beyond the internal oxidation zone. However, the internal oxide zone was deeper beneath cracks (see Figure 3).

\section{Mechanical Tests}

Tensile test results for room temperature, $538^{\circ} \mathrm{C}, 650^{\circ} \mathrm{C}$ and $760^{\circ} \mathrm{C}$ are shown in Table IV. It can be seen from the data that alloy 909 was stronger than 242 alloy at all temperatures.

Results of stress-rupture tests at $540^{\circ} \mathrm{C}, 595^{\circ} \mathrm{C}, 650^{\circ} \mathrm{C}, 705^{\circ} \mathrm{C}$ and $760^{\circ} \mathrm{C}$ are shown in Figure 4. At $540^{\circ} \mathrm{C}$ and $595^{\circ} \mathrm{C}$, the rupture lives for the two alloys were similar, whereas at temperatures of $650^{\circ} \mathrm{C}$ and higher, 242 alloy exhibited longer lives. The stress rupture samples were sectioned after testing and the depth of oxidation attack measured. The measurements are listed in Table V. The extent of oxidation was observed to be much greater in alloy 909. 


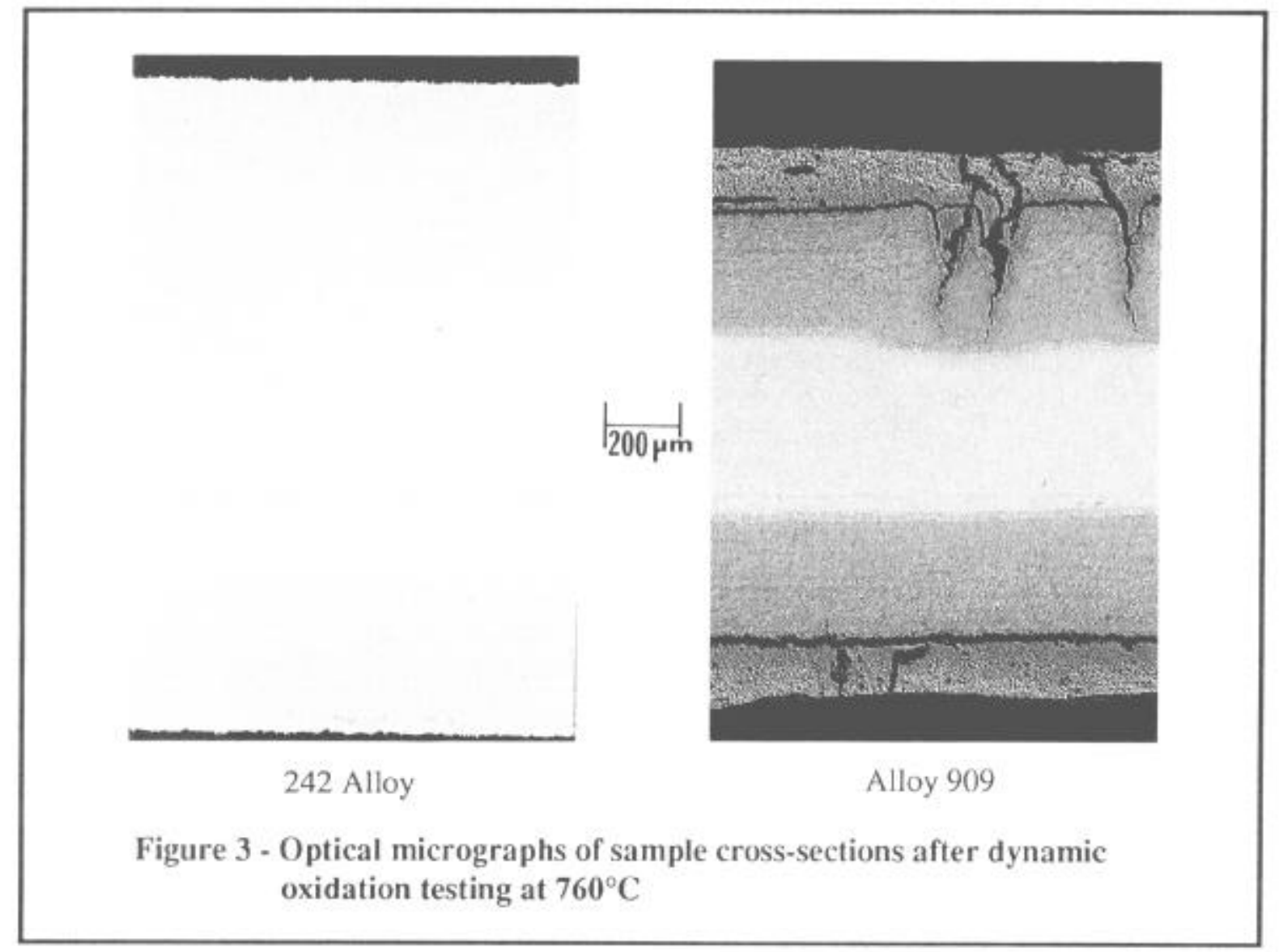

\section{Table IV Tensile Properties at Room Temperature and Elevated Temperature}

\begin{tabular}{lcccc} 
Alloy & Temp. $\left({ }^{\circ} \mathrm{C}\right)$ & YS $(\mathrm{MPa})$ & UTS $(\mathrm{MPa})$ & El. $(\%)$ \\
\hline 242 & RT & 757.4 & 1236 & 39.3 \\
& 538 & 491.2 & 1001 & 45.7 \\
& 650 & 524.1 & 980.4 & 43.1 \\
& 760 & 287.2 & 730.2 & 66.3 \\
909 & & & 1328.1 & 10.5 \\
& & 1053.2 & 1121.8 & 13.6 \\
& RT & 894.2 & 1069.5 & 16.2 \\
& 538 & 845.2 & 674.0 & 26.8 \\
\hline
\end{tabular}

In fatigue testing, stress-controlled tests were conducted at $650^{\circ} \mathrm{C}$ on double-notched specimens. The results are presented in Figure 5. At high stress and relatively low cycles to failure alloy 909 was favored. At lower stresses and longer times the 242 alloy was superior.

Fatigue tested samples were examined using optical metallography. The 909 sample exhibited numerous secondary cracks associated with the primary fracture. The fracture surface was heavily oxidized. A single secondary crack was observed on the 242 sample, and oxidation attack was observed to be minimal. 


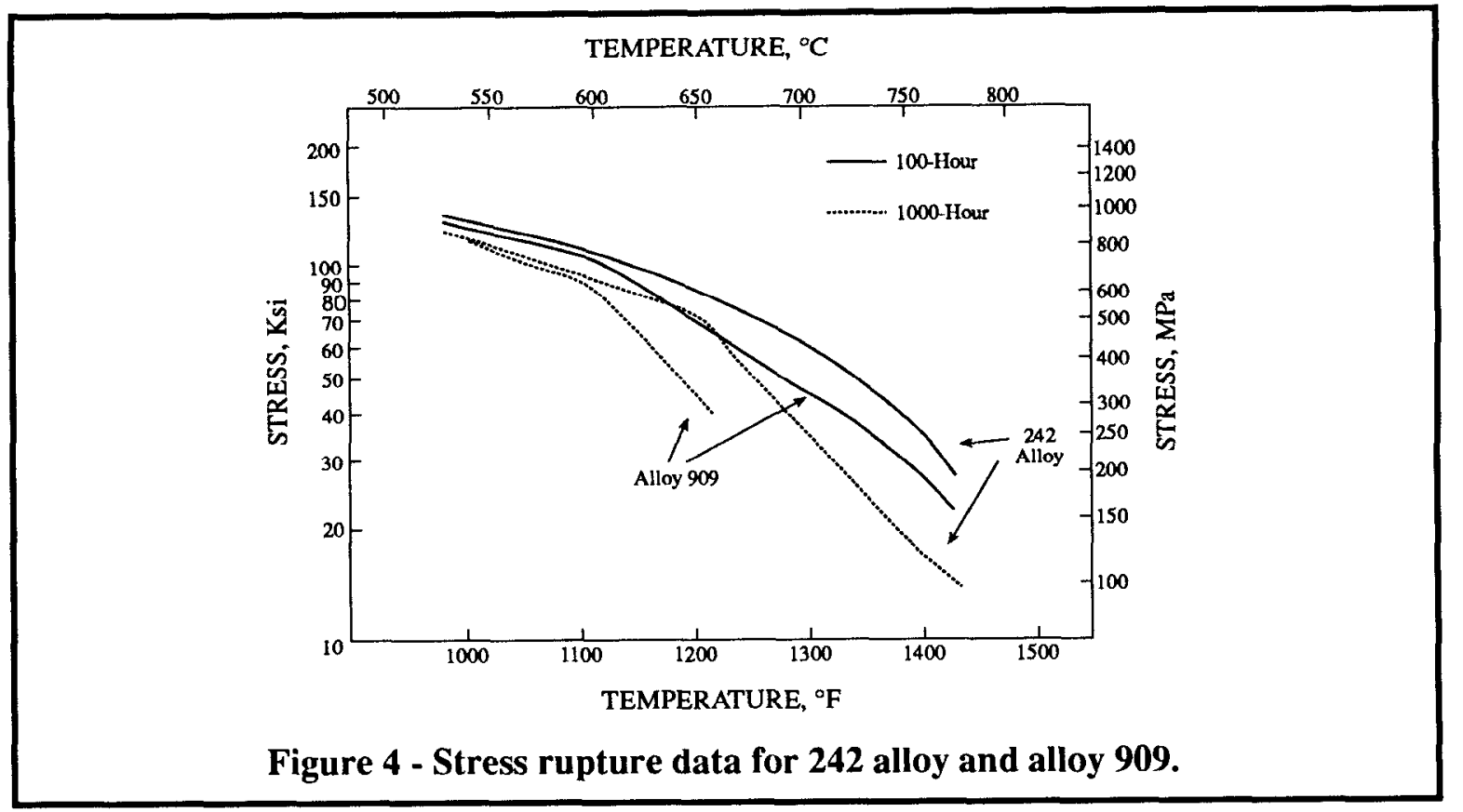

Table V Measurement of Oxidation on Stress Rupture Specimens

\begin{tabular}{|c|c|c|c|c|c|c|}
\hline \multicolumn{4}{|c|}{$650^{\circ} \mathrm{C} / 621 \mathrm{MPa}$} & \multicolumn{3}{|c|}{$760^{\circ} \mathrm{C} / 172 \mathrm{MPa}$} \\
\hline Alloy & $\begin{array}{l}\text { Rupture } \\
\text { Life (h) }\end{array}$ & $\begin{array}{l}\text { Scale } \\
(\mu \mathrm{m})\end{array}$ & $\begin{array}{c}\text { Maximum } \\
\text { Int. Attack } \\
\quad(\mu \mathrm{m})\end{array}$ & $\begin{array}{l}\text { Rupture } \\
\text { Life (h) }\end{array}$ & $\begin{array}{l}\text { Scale } \\
(\mu \mathrm{m})\end{array}$ & $\begin{array}{l}\text { Maximum } \\
\text { Int. Attack } \\
\quad(\mu \mathrm{m})\end{array}$ \\
\hline 909 & 38.2 & 114.3 & 101.6 & 130.5 & 101.6 & $63.5^{*}$ \\
\hline 242 & 63.2 & 0 & 50.8 & 323.8 & 0 & 114.3 \\
\hline
\end{tabular}

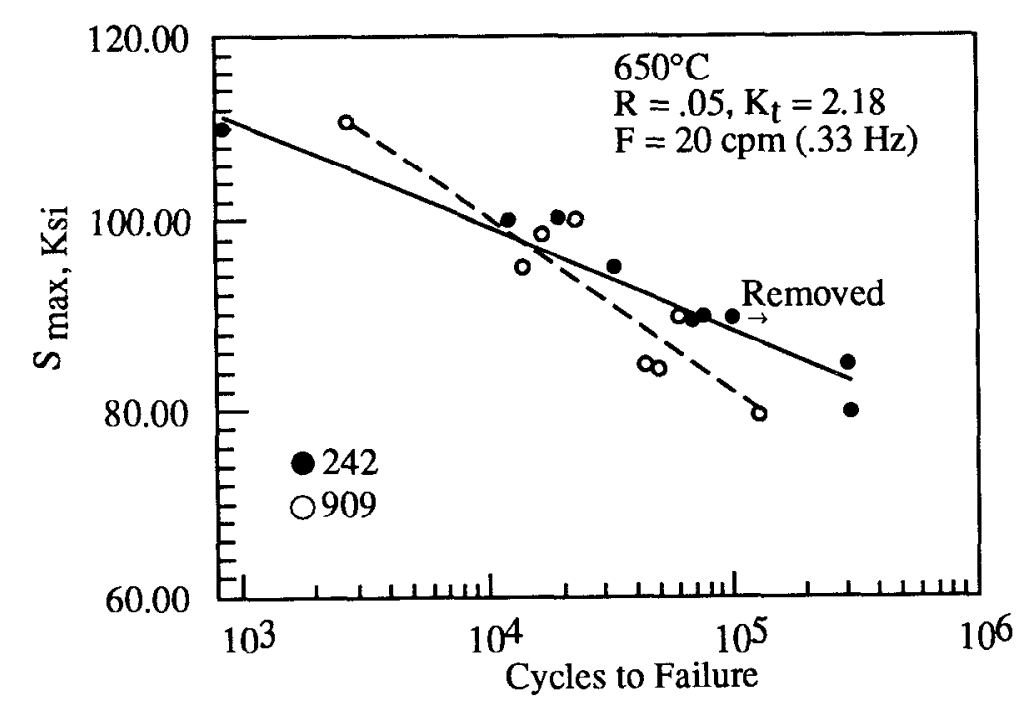

Figure 5 - LCF data for 242 alloy and alloy 909 under stress controlled conditions at $650^{\circ} \mathrm{C}$. 


\section{Discussion}

The oxidation resistance of an alloy is an important feature in its ability to withstand the conditions encountered in a gas turbine engine. The deleterious effects of oxidation are twofold : metal loss, resulting in reduction of the load- bearing cross-section; and scale formation and internal oxidation, which provide a brittle layer for initiation of cracks. Fatigue crack propagation is also facilitated by oxidation effects.

Alloy 909 and 242 alloy exhibited very different oxidation behavior. Alloy 909 , which is devoid of chromium, oxidized at a rapid rate. The alloy formed a thick scale and extensive internal oxides. In the static oxidation test, which imposed a relatively mild thermal stress, the alloy underwent interfacial cracking at the scale/metal interface and extensive delamination of the scale took place.

In the dynamic oxidation test, which imposed much greater thermal stress on the materials, alloy 909 exhibited cracks extending through the internal oxidation zone in addition to interfacial cracks. The cracks gave rise to deeper internal oxidation than in areas which were crack-free. The depth of internal oxidation in the dynamic oxidation test was much greater than that in the static oxidation test of the same duration (see Tables II \& III). The cracks appeared to have little effect on the oxidation mechanism, given that a parabolic rate law was still obeyed. The parabolic law indicates that diffusion through a boundary layer is the controlling step. Cracking under thermal stress is a clear indication of the brittle nature of the oxide scale and subscale. The stress generated during thermal cycling, which is a function of the thermal expansion difference between the oxide and metal and the magnitude of the temperature change, apparently exceeds the critical stress level in the oxide. It is clear that the imposition of an external tensile stress which exceeds the critical stress level in the oxide will result in similar cracking and acceleration of oxidation.

In contrast to alloy 909 , the 242 alloy oxidized at a low rate in both the static and dynamic tests, forming a thin, adherent, chromium-rich scale. The scale was not adversely affected by the thermal stresses generated in the dynamic oxidation test.

With the exception of the tensile properties, the difference in the oxidation behavior of the two alloys was reflected in their mechanical behavior. The tensile test is a relatively short term test which demonstrates the inherently high strength of alloy 909 , and, thus, there was little oxidation of alloy 909 which might cause a deterioration in strength. The stress rupture test, on the other hand, subjects the specimen to a relatively long term tensile stress.

The stress rupture results showed that at higher temperatures $\left(650^{\circ} \mathrm{C}\right.$ and higher) the 242 alloy was much stronger than alloy 909 . This is probably an effect of the much higher oxidation rates at the higher temperatures. The extent of oxidation during the stress rupture test (Table V) was much greater than that from the static oxidation test, which was of much longer duration. It is apparent that cracking of the oxide under tensile stress greatly increases the extent of internal oxidation.

In the fatigue test, cracks in the subscale such as those observed in the dynamic oxidation test, would undoubtedly initiate fatigue cracks. It was found that at lower stresses and longer times alloy 909 was inferior to 242 alloy. The 909 material exhibited many secondary cracks, and the primary fracture was heavily oxidized. The subscale cracks, which are a feature of the alloy 909 oxidation even under the influence of thermal stresses, undoubtedly accelerate the failure of the alloy under fatigue conditions. The 242 alloy, which is not susceptible to oxide cracking under stress, exhibited minor secondary cracking and little oxidation of the primary fracture. 


\section{Conclusions}

The critical importance of oxidation resistance in the overall performance of an alloy at high temperature has been demonstrated. The poor oxidation resistance of alloy 909 led to lower mechanical properties in those tests in which the alloy was exposed to high temperatures for a long period of time. The alloy suffered subscale cracking under the imposition of relatively small thermal stresses. This was exacerbated by the imposition of external tensile stresses, leading to more extensive cracking and accelerated oxidation. The 242 alloy, by contrast, had good oxidation resistance and consequently good long term mechanical properties.

\section{References}

1) S.K. Srivastava and M.F. Rothman, "An Advanced Ni-Mo-Cr Alloy for Gas Turbines", in High Temperature Materials for Power Engineering, (Dordrecht, NL : Kluwer Academic Publishers, 1990), 1357-1366.

2) S.K. Srivastava : "A Low Thermal Expansion, High Strength Ni-Mo-Cr Alloy for Gas Turbines", this conference.

3) P.N. Chaku and C.J. McMahon, "Effect of an Air Environment on the Creep and Rupture Behavior of a Ni-Base High Temperature Alloy," Metall. Trans., 5 (1974), 451-450.

4) L.F. Coffin, "Fatigue at High Temperature," in Fatigue at Elevated Temperatures, ASTM STP 520, (Philadelphia : American Society for Testing and Materials, 1973), 5-34

5) C.J. McMahon and L.F. Coffin, "Mechanisms of Damage and Fracture in High-Temperature, Low-Cycle Fatigue of a Cast Nickel-Based Superalloy," Metall. Trans., 1 (1970), 3443-50

6) L.F. Coffin, "The Effect of Vacuum on the High Temperature Low Cycle Fatigue Behavior of Structural Metals," in Corrosion Fatigue, NACE 2, ed. O.F. Devereux, A.J. McEvily, and R.W. Staehle (Storrs, CT : National Association of Corrosion Engineers, 1972), 590-599.

7) L.F. Coffin : in Fracture 1977, ICF 4, Waterloo, ON, Canada, June 19-24, 1977, vol. 1, 263-292

8) D.A. Woodford, "Environmental Damage of a Cast Nickel-Based Superalloy," Metall. Trans., 12A (1981), 299-308. 